\title{
Twenty-first century regional temperature response in Chile based on empirical-statistical downscaling
}

\author{
Sebastian G. Mutz ${ }^{1}$ id $\cdot$ Samuel Scherrer ${ }^{1,2} \cdot$ Ilze Muceniece $^{1} \cdot$ Todd A. Ehlers $^{1}$
}

Received: 7 July 2020 / Accepted: 28 December 2020 / Published online: 23 January 2021

(C) The Author(s) 2021

\begin{abstract}
Local scale estimates of temperature change in the twenty-first century are necessary for informed decision making in both the public and private sector. In order to generate such estimates for Chile, weather station data of the Dirección Meteorológica de Chile are used to identify large-scale predictors for local-scale temperature changes and construct individual empiricalstatistical models for each station. The geographical coverage of weather stations ranges from Arica in the North to Punta Arenas in the South. Each model is trained in a cross-validated stepwise linear multiple regression procedure based on (24) weather station records and predictor time series derived from ERA-Interim reanalysis data. The time period 1979-2000 is used for training, while independent data from 2001 to 2015 serves as a basis for assessing model performance. The resulting transfer functions for each station are then directly coupled to MPI-ESM simulations for future climate change under emission scenarios RCP2.6, RCP4.5 and RCP 8.5 to estimate the local temperature response until 2100 A.D. Our investigation into predictors for local scale temperature changes support established knowledge of the main drivers of Chilean climate, i.e. a strong influence of the El Niño Southern Oscillation in northern Chile and frontal system-governed climate in central and southern Chile. Temperature downscaling yields high prediction skill scores (ca. 0.8), with highest scores for the midlatitudes. When forced with MPI-ESM simulations, the statistical models predict local temperature deviations from the 1979-2015 mean that range between $-0.5-2 \mathrm{~K}, 0.5-3 \mathrm{~K}$ and 2-7 K for RCP2.6, RCP4.5 and RCP8.5 respectively.
\end{abstract}

Keywords Empirical statistical downscaling $\cdot$ Chile $\cdot$ Climate change $\cdot$ Statistical modelling $\cdot$ Prediction

\section{Introduction}

The wide-reaching observed and predicted ecological and socioeconomic consequences of contemporary climate change (IPCC AR5 2014) create a demand for regionalscale estimates of twenty-first century climate evolution to allow careful planning in both public and private sectors to mitigate impacts (IPCC AR5 2014). One tool to achieve this is General Circulation Models (GCMs), which are based on

Supplementary Information The online version contains supplementary material available at https://doi.org/10.1007/s0038 2-020-05620-9.

Sebastian G. Mutz

sebastian.mutz@uni-tuebingen.de

1 Department of Geosciences, Universität Tübingen, Tübingen, Germany

2 Present Address: Department of Geodesy and Geoinformation, Technische Universität Wien, Vienna, Austria our understanding of atmospheric physics and allow us to model climates in dynamic equilibrium with prescribed forcings. The Representative Concentration Pathways (RCPs) describe different forcing scenarios that correspond to possible trajectories of demographic and technological developments (IPCC AR5 2014), and drive GCMs to simulate possible near future (twenty-first century) climates. While GCMs generally offer accurate estimates of many elements of the climate system, meso-scale processes are often poorly represented, leading to inaccurate estimates of aspects of climate change on a more regional scale (e.g. Meehl et al. 2007). However, these estimates are needed to assess regional-scale impacts, such as changes in the hydrological cycle (DiazNieto and Wilby 2005), glacial retreat (Mutz et al. 2015), air quality (Hogrefe et al. 2004), local industry and human health (Patz et al. 2005), and allow for effective planning and mitigation strategies. The GCMs' shortcomings on such scales are typically circumvented by dynamical downscaling with Regional Climate Models (RCMs) (e.g. Maussion et al. 
2011; Mannig et al. 2013), or statistical downscaling (e.g. Eden et al. 2012).

Empirical statistical downscaling (ESD) is an umbrella term for methods that statistically relate local expressions of the climate system, such as temperature or precipitation recorded at weather stations, to relevant synoptic- to mesoscale atmospheric variability (e.g. Hewitson et al. 2014). For example, coarse climate model output with locationdependent systematic errors in rainfall may be fitted to local-scale observational data of rainfall (e.g. Eden et al. 2012). The resulting statistical model may then be coupled to climate or weather model output and use these large-scale conditions as predictors for local-scale rainfall, i.e. the target variable or predictand. Such statistical modelling is well established in the climatological and meteorological community (e.g. Glahn and Lowry 1972; Hansen and Emanuel 2003; Shongwe et al. 2006; Paeth 2011; Mutz et al. 2015). It is computationally less expensive than dynamical downscaling and implicitly takes in-situ geographical realities, such as local topography and micro-climate controls, into consideration without the need to explicitly parameterise these as is the case for RCMs. Furthermore, statistical downscaling avoids propagation of systematic errors by GCMs and errors pertaining to parameterisation schemes (e.g. Errico et al. 2001; Hewitson et al. 2014). While dynamical downscaling over South America has significantly advanced in the past two decades (Solman 2013; Giorgi and Gutowski 2013), the ESD community in South America is incipient. The potential for ESD in the region has not been explored as thoroughly as in other parts of the world (CORDEX 2020). The high potential for ESD is demonstrated by the dense network of automated weather station (AWS) maintained by the Meteorological Directorate of Chile (Fig. 1), and researched links between regional climate and synoptic-scale atmospheric variability, such the Antarctic Oscillation (Garreaud et al. 2013).

Chile's large latitudinal extent and prominent orography lead to a variety of synoptic- and meso-scale climate controls. The El Niño Southern Oscillation (ENSO), South Pacific Anticyclone (SPA) and mid-latitude westerlies are important controls on climate and weather in Chile (Fig. 2). This results in large temperature and precipitation gradients in Chile (Fig. 3). ENSO affects northern Chile directly, leading to anomalously high temperature and precipitation during El Niño phases relative to non-El Niño phases (e.g. Rutllant and Fuenzalida 1991; Garreaud et al. 2009), and impacts southern Chile indirectly via atmospheric teleconnections (e.g. Garreaud et al. 2009). The Andes mountains cool sea surface temperatures (SSTs) off the west coast of South America by evaporative cooling, thereby creating an enhanced North-to-South cooling gradient in the east Pacific that deflects the intertropical convergence zone (ITCZ) and related convective precipitation north (Takahashi and

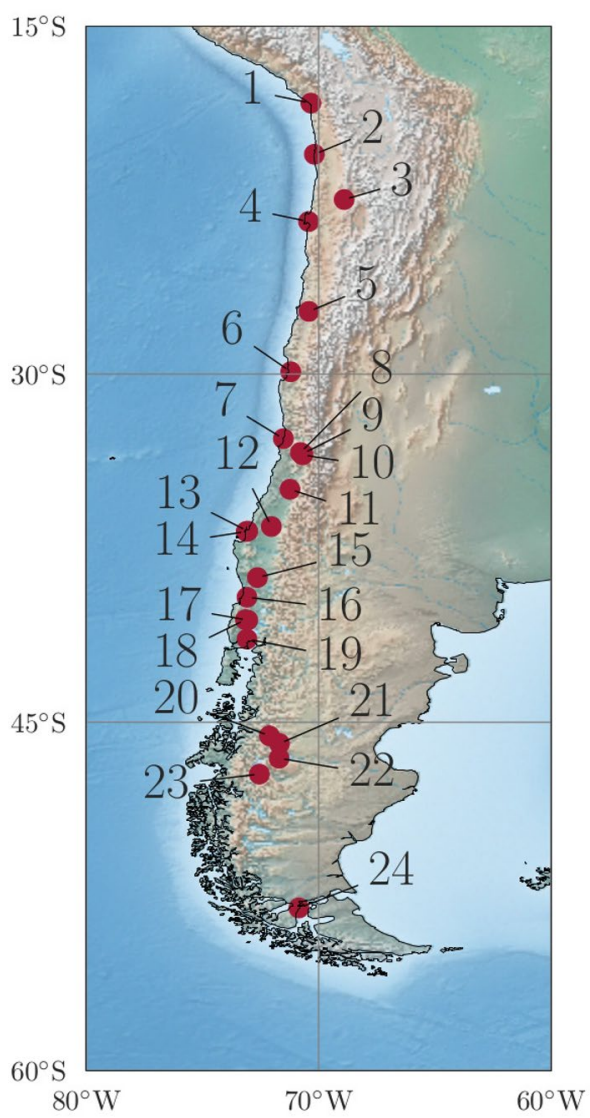

Fig. 1 Topography and location of the 24 numbered weather stations in Chile. The stations are numbered by their latitudinal position with 1 being the northernmost station and 24 being the southernmost station. See supplemental Table 1 for station information

Battisti 2007). The extreme aridity in northern Chile can be explained by a cold marine boundary layer (MBL) and subsidence associated with the quasi-permanent SPA (Fig. 2), which is stabilised by the cold SSTs associated with the Humboldt current. When combined, these processes create a thermal inversion that drastically inhibits convection and rainfall. A stratocumulus layer forms in the upper MBL, thereby reducing solar insolation below and ensuring cold (near-)surface temperatures (Rutllant et al. 2003). Furthermore, the Andes create a topographic barrier that prevents advection of moist air from the East, thus contributing to northern Chile aridity. Variations in aridity can, at least in parts, be explained by the Pacific Decadal Oscillation (e.g. Schulz et al. 2011), a multidecadal mode of climate variability in the Pacific (Mantua and Hare 2002). While the Pacific Decadal Oscillation (PDO) shows links to lowfrequency fluctuations in precipitation in northern Chile, connections between low-frequency precipitation fluctuations and the Atlantic Multi-Decadal Oscillation (AMO) are significant in north and south Chile (Valdés-Pineda et al. 2018). The Antarctic Oscillation (AAO) (Rogers and Loon 


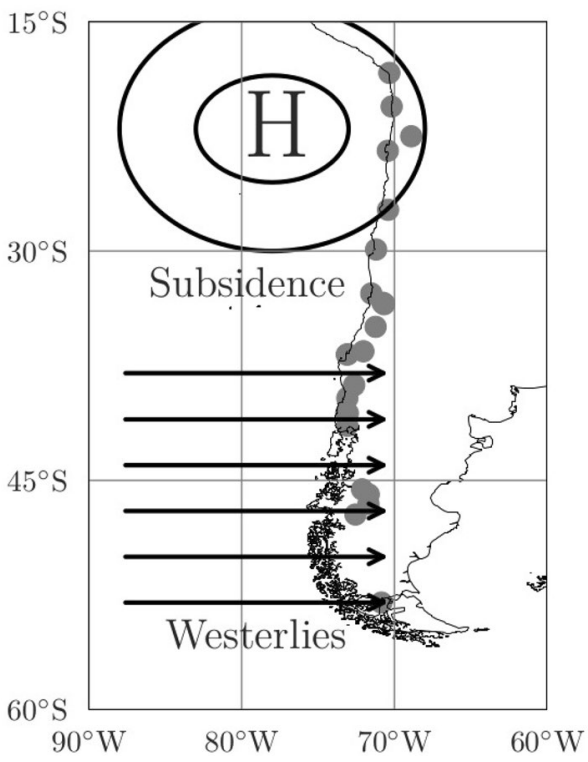

Fig. 2 The major large-scale controls on Chilean climate on the 24 weather stations (grey circles) include a more direct influence of the El Niño Southern Oscillation (ENSO) and the South Pacific Anticyclone (SPA) and subsidence in the north, and mid-latitude westerlies in more southern parts of Chile
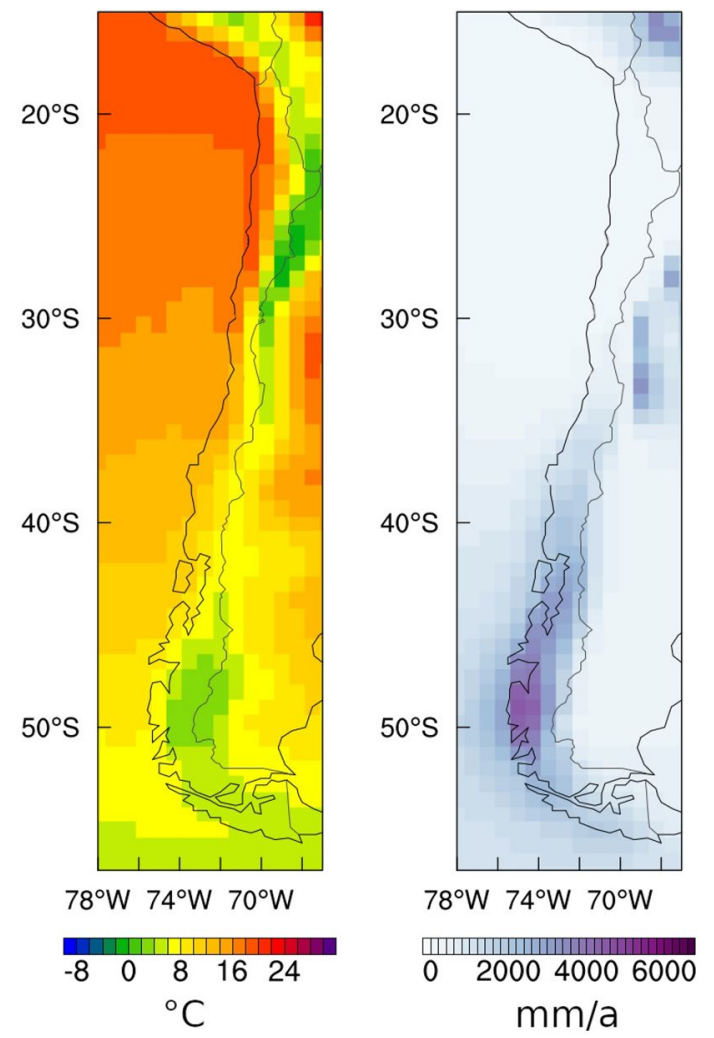

Fig. 3 ERA-Interim mean annual near surface $(2 \mathrm{~m})$ temperatures (left) and mean annual precipitation (right) highlight the pronounced climate gradients in Chile due to orographic and latitude-specific forcings
1982; Thompson and Wallace 2000) is related to a low pressure field above Antarctica and the belt of westerly winds around it. The AAO is partially coupled to ENSO (Fogt and Bromwich 2006). A positive AAO phase is associated with anomalously low pressure over Antarctica and relatively high pressure in Southern Hemisphere mid-latitudes, and results in the contraction of the belt of westerlies; this directs westerlies southward and thus impacts temperature and rainfall variation in south Chile (e.g. Gillett et al. 2006). More specifically, a positive mode of AAO is associated with increased surface pressure, warmer temperature, and lower precipitation south of $40^{\circ} \mathrm{S}$ (e.g. Garreaud et al. 2009). ENSO and AAO are related to higher frequency changes in precipitation, esp. in northern and southern Chile respectively, whereas the PDO and AMO affect low-frequency variability (Valdés-Pineda et al. 2018). Finally, the uplift of low-level westerly winds over the western side of the Andes produces strong orographic precipitation in southern Chile (esp. the Patagonia region).

This study complements previous regional studies of Chilean climate and estimates of future climate change in South America by investigating large-scale climatic controls on regional climate, and downscaling GCM-based temperature estimates for the twenty-first century. The specific aims of the study are:

1. To find large-scale predictors for local temperatures based on existing knowledge of Chilean climatology, and to quantify their predictive skill.

2. To train empirical-statistical downscaling models for a set of 24 suitable meteorological stations, and to test their performance.

3. To apply the trained models to GCM simulations of twenty-first century climates to estimate local temperature responses to different forcing scenarios.

We address these aims by (a) training the statistical models for a set of suitable meteorological stations across Chile with appropriate synoptic and meso-scale predictors, thus building on previous studies of Chilean climate, and (b) applying ESD directly to GCM output, thus circumventing the (computationally) expensive intermediate step of RCM nesting.

\section{Data and methods}

\subsection{Weather Stations}

Weather station data of the Dirección Meteorológica de Chile (DMC) was digitised to serve as predictand time series for the ESD models developed for this study. These models are empirical in nature and therefore require sufficiently long 
records of observation for training and validation. Weather stations with short records were thus excluded from the study. There is no universally valid threshold for the number of years of observational data required for training, since the goodness of the model is partially determined by whether or not the predominant predictor-predictand relationships are observed in the recorded time window (e.g. Hewitson et al. 2014). To ensure the inclusion of potentially useful short weather station records, the minimum record length is set to 10a. The models are calibrated using monthly means of $2 \mathrm{~m}$ air temperature with previously filtered annual cycle. Therefore, only data with temporal resolution of at least 1 month was included. The 24 weather stations that fulfill these criteria cover the latitudinal span of Chile, as well as different altitudinal ranges and proximity to the Pacific Ocean and the Andes. A summary of station ID's, names, coordinates and altitude of their location is provided in Table 1 .

\subsection{ERA-interim reanalysis}

ERA-Interim reanalyses provided by the ECMWF (European Centre for Medium Range Weather Forecasting) are based on records from various observation systems that are dynamically interpolated with numerical forecasting in a data assimilation scheme to produce a spatially homogenous global dataset covering the time period from 1979 to present-day (Dee et al. 2011). Its spatial resolution corresponds approximately to a horizontal $80 \times 80 \mathrm{~km}$ grid with 60 vertical levels from the surface to $0.1 \mathrm{hPa}$, and has a temporal resolution of $6 \mathrm{~h}$. For the purposes of this study, monthly values of $2 \mathrm{~m}$ air temperature $(\mathrm{t} 2 \mathrm{~m})$, mean sea level pressure (msl), zonal wind at $850 \mathrm{hPa}(\mathrm{u} 850)$, meridional wind at $850 \mathrm{hPa}(\mathrm{v} 850)$ and geopotential height at $700 \mathrm{hPa}(\mathrm{h} 700)$ are derived from the dataset.

\subsection{GCM simulations}

General Circulation Models (GCMs) simulate global climate on the basis of our understanding of atmospheric physics. They are a well established tool in atmospheric sciences and used to investigate atmospheric processes, contemporary climate change (IPCC 2014 and references therein) and reconstruction of past climates (e.g. Haywood et al. 2010, Bracannot et al. 2012, Mutz et al. 2018). GCMs simulate climates in dynamic equilibrium with the prescribed boundary conditions. When those boundary conditions correspond to various RCP (Representative Concentration Pathways) scenarios, reflecting climate forcings due to possible demographic and technological developments in the near future (Moss et al. 2010), GCMs are able to provide estimates of
Table 1 Weather station IDs, names, locations (latitude, longitude and altitude above sea level)

\begin{tabular}{|c|c|c|c|c|}
\hline ID & Name & Lat & Lon & Altitude (m) \\
\hline 1 & Arica Chacalluta & -18.3333 & -70.3333 & 58 \\
\hline 2 & Iquique Diego Aracena & -20.5333 & -70.1833 & 52 \\
\hline 3 & Calama El Loa & -22.4833 & -68.9 & 2270 \\
\hline 4 & Antofagasta Cerro Moreno & -23.4333 & -70.4333 & 135 \\
\hline 5 & Copiapo Chamonate & -27.3 & -70.4167 & 291 \\
\hline 6 & La Serena La Florida & -29.9 & -71.2 & 142 \\
\hline 7 & Quintero & -32.7833 & -71.5167 & 8 \\
\hline 8 & Santiago Pudahuel & -33.3833 & -70.7833 & 475 \\
\hline 9 & Santiago Quinta Normal & -33.4333 & -70.6833 & 520 \\
\hline 10 & Santiago Los Cerillos & -33.4833 & -70.6833 & 519 \\
\hline 11 & Curico General Friere & -34.966667 & -71.2333 & 228 \\
\hline 12 & Chillan B O Higgins & -36.5667 & -72.0333 & 124 \\
\hline 13 & Concepcion Carriel Sur & -36.7667 & -73.05 & 12 \\
\hline 14 & Bellavista U Concepcion & -36.7833 & -73.1167 & 15 \\
\hline 15 & Temuco Maquehue & -38.7667 & -72.6333 & 114 \\
\hline 16 & Valdivia Pichoy & -39.6167 & -73.0833 & 19 \\
\hline 17 & Osorno Canal Bajo & -40.6 & -73.05 & 65 \\
\hline 18 & J.Kalt Bode & -40.583333 & -73.15 & 50 \\
\hline 19 & Puerto Montt el Tepual & -41.4167 & -73.083333 & 85 \\
\hline 20 & Coyhaique Teniente Vidal & -45.5833 & -72.1167 & 310 \\
\hline 21 & Balmaceda & -45.9167 & -71.6833 & 520 \\
\hline 22 & Chile Chico Aerodromo & -46.55 & -71.7 & 328 \\
\hline 23 & Lord Cochrane Aerodromo & -47.2333 & -72.55 & 169 \\
\hline 24 & Punta Arenas Carlos Ibanez & -53 & -70.85 & 37 \\
\hline
\end{tabular}


possible future climates (IPCC 2014 and references therein). Simulations of the Max Planck Institute (MPI) Earth System Model (ESM) MPI-ESM, as provided by the World Climate Research Programme's (WCRP) Coupled Model Intercomparison Project phase 5 (CMIP5) (Taylor et al. 2012), provide the basis for the downscaling efforts of this study. More specifically, the trained ESD models (Sect. 2.5) are driven with MPI-ESM simulations based on RCP scenarios of RCP2.6, RCP4.5 and RCP8.5 (Moss et al. 2010), so that the downscaling results represent local-scale responses to a wide range of possible future scenarios. In addition to these simulations, Atmospheric Model Intercomparison Project (AMIP) style simulations for present-day climate are coupled to the ESD models and used for calibration.

\subsection{Predictors}

\subsubsection{Selection criteria}

Prior to automatic selection and elimination of predictors in the model training procedure (Sect. 2.5), a set of reasonable predictors must be identified. Two major criteria have to be met by predictors in this pre-selection step: (1) Physical relevance to the predictand and (2) adequate representation of predictors in GCMs. The reasons for these restrictions are as follows:

1. In ESD models, predictors represent the large-scale atmospheric variability that is physically related and empirically relevant to the prediction of the local-scale atmospheric variability of predictands at each of the weather stations. Since the training of these models is based solely on empirical relationships, a careful selection of physically meaningful predictors ensures that physically irrelevant variables showing spurious correlations with predictands in the observation time period are not included in the models. Therefore, the predictors in Table 2 were chosen. Details about their construction are given below.

2. The ESD models in this study are based on training with ERA-interim reanalyses are part of the family of models based on the Perfect Prognosis (PP) rather than Model Output Statistics (MOS) approach (Lowry and Glahn 1969). While MOS fits the ESD models with simulated predictor data, such as output produced by GCMs, the PP approach has the advantage of training based on observational records (weather station and reanalysis data). This approach is chosen to allow better physical interpretation of model transfer functions. As a result of choosing the PP approach, further restrictions have to be placed upon the selection of predictors. Since the PP approach does not take model biases into account implicitly, as is the case for MOS-style model training,
Table 2 Acronym and full name of predictors used in the training of empirical-statistical downscaling models

\begin{tabular}{ll}
\hline Acronym & Full name \\
\hline MEI & Multivariate El Niño/Southern Oscillation (ENSO) Index \\
AAOI & Antarctic Oscillation Index \\
PDOI & Pacific Decadal Oscillation Index \\
t2m & 2 m air temperature \\
Msl & Mean sea level pressure \\
u850 & Zonal wind speed component at $850 \mathrm{hPa}$ \\
u850 & Meridional wind speed component at $850 \mathrm{hPa}$ \\
h700 & Geopotential height at $700 \mathrm{hPa}$ \\
\hline
\end{tabular}

and the ESD models are coupled to GCM simulations, the chosen predictors have to be adequately represented in GCMs to ensure more robust estimates.

\subsection{Predictor construction}

For downscaling of temperature at least one atmospheric circulation describing predictor (e.g. sea level pressure) and one temperature predictor (e.g. $2 \mathrm{~m}$ air temperature) should be included in the training procedure (Huth 2002). For each station, regional (500 km scale) means of $2 \mathrm{~m}$ air temperature $(\mathrm{t} 2 \mathrm{~m})$, mean sea level pressure $(\mathrm{msl})$, geopotential height at $700 \mathrm{hPa}(\mathrm{h} 700)$, and meridional and zonal winds at $850 \mathrm{hPa}$ (v850 and u850 respectively) were used. Due to the known influence of ENSO (e.g. Rutllant and Fuenzalida 1991) and the AAO (e.g. Garreaud et al. 2009) on climate in northern and southern Chile respectively, indices for these atmospheric phenomena serve as additional predictors. For the former, the Multivariate ENSO Index (MEI) (Wolter and Timlin 1993) was computed by means of a principal component analysis (PCA) without the clustering step, following the approach of Wolter and Timlin (2011). The loading patterns associated with this particular index are shown in supplemental figure S01. Furthermore, the inclusion of cloudiness was omitted following the ECMWF's recommendations due to inconsistencies in its calculations (Hennermann 2016). An index for the atmospheric variability associated with the AAO (AAOI) was computed in another PCA by projecting the $700 \mathrm{hPa}$ anomaly field south of $20^{\circ} \mathrm{S}$ onto the loading patterns from the Climate Prediction Center (CPC) at the National Centers for Environmental Prediction (NCEP) (NOAA-CPC 2020). Finally, following (Garreaud et al. 2009), the first principal component of Pacific SST anomalies north of $20^{\circ} \mathrm{N}$ was used as an index for the PDO (PDOI). For consistency, the same ENSO, AAO and PDO loading patterns were used for calculating the MEI AAOI and PDOI from GCM output for the investigated RCPs. 
The full set of predictors described above is summarised in Table 1.

\subsection{Model training and validation}

The climatic and geographic setting for the 24 weather stations (Sect. 2.1) are highly varied. One of the strengths of ESD is the implicit consideration of highly localised conditions. We exploit this strength in this study by training models for the 24 stations separately using linear parametric models. Such models are commonly used in downscaling (e.g. Huth 2002; Zorita and von Storch 1999) due to the ease of interpretation of results, a possible increase predictive ability due to restriction of function complexity (Hastie et al. 2001) and better predictive ability outside the training data value range when compared to equivalents such as Random Forests regressions (e.g. Pollinger et al. 2017). At its core, model training consists of a cross-validated stepwise multiple linear regression procedure with random bootstrapping and forward selection (e.g. von Storch and Zwiers 1999). The models themselves comprise a set of constants and transfer functions that linearly relate a set of predictors, denoted as the matrix $\mathbf{X}$, to the predictand $\mathbf{y}$. More specifically, an additive model was assumed, such that:

$y=\beta_{0}+\beta \cdot X+\varepsilon$,

where $\varepsilon$ is the variance of $y$ that cannot be explained by the set of predictors $\mathbf{X}$, vector $\boldsymbol{\beta}$ comprises the regression coefficients for each of the large-scale predictors and represents their influence on a local-scale predictand, and vector $\beta_{0}$ is the $y$ intercept of the linear function that includes constant local effects and will no longer be mentioned from here on for the sake of brevity. For m number of predictors and $\mathrm{n}$ observations, $\mathbf{y}, \boldsymbol{\beta}$ and $\mathbf{X}$ are:

$\left(\begin{array}{c}y_{1} \\ y_{2} \\ \vdots \\ y_{n}\end{array}\right),\left(\begin{array}{c}\beta_{1} \\ \beta_{2} \\ \vdots \\ \beta_{m}\end{array}\right)$ and $\left(\begin{array}{c}x_{11} x_{12} \ldots x_{1 m} \\ x_{21} x_{22} \ldots x_{2 m} \\ \vdots \\ x_{n 1} x_{n 2} \ldots x_{n m}\end{array}\right)$.

The model is fitted with observation-based (ERA-interim) data and thus belongs to the Perfect Prognosis rather than the Model Output Statistics model families (Lowry and Glahn 1969). The total record length $\mathrm{n}$ for each station is subdivided into training (1979-2000) and validation (2001-2015) periods. The focus lies on models trained from 1979 to 2000 and validated in 2001-2015, following established conventions (e.g. CORDEX 2020). Additional models are trained from 2001 to 2015 and the full observational period 1979-2015 to evaluate the sensitivity of results to ESD model training periods. For data within the training period, the model is trained through a successive set of iterations. For each iteration, a random set of observations is retained for in-training cross-validation (Michaelsen 1987). For this, contiguous blocks of data are excluded following recommendations for potentially auto-correlated data (Roberts et al. 2017) to avoid overfitting. This results in the exclusion of a third of the data. For the remaining data, the above problem is solved using a multivariate ordinary least-squares (OSL) regression on a subset of predictors, yielding parameter estimates $\hat{\beta}$ that allow prediction $\hat{y}$ for the retained data of the validation set. In the forward selection approach (e.g. von Storch and Zwiers 1999; Mutz et al. 2015), the initial models start with an empty set of predictors and predictors are added to the set successively if they contribute to the significant improvement of the model. The measure for significant improvement is an increase in the variance of $\mathbf{y}$ that can be explained by the inclusion of the predictor into the model. This was assessed by computation of the coefficients of multiple determination $\left(\mathrm{R}^{2}\right)$ :

$R^{2}=1-\frac{\sum_{i=1}^{n}\left(y_{i}-\widehat{\beta}_{0}-\sum_{j=1}^{m} \widehat{\beta}_{j} \cdot x_{i j}\right)^{2}}{\sum_{i=1}^{n}\left(y_{i}-\bar{y}\right)^{2}}$

following a full multiple regressions for the current active set of predictors and every predictor not yet included (von Storch and Zwiers 1999). The distance of predicted from observed predictand values, i.e. the general model accuracy, is given by the root mean square error:

$R M S E=\sqrt{\frac{\sum_{i=1}^{n}\left(\hat{y}_{i}-y_{i}\right)^{2}}{n}}$

Once the RMSE decreases following the inclusion of a predictor, the predictor in question is excluded and the predictor set for the iteration is established. After completion of all iterations, the model for each station is finalised by averaging $\hat{\beta}$ over all iterations and imposing a robustness filter that permits inclusion of a predictor into the final model only if it significantly increased the explained variance of $\mathbf{y}$ in at least $50 \%$ of all iterations (Mutz et al. 2015). Once the models are constructed, they are applied to predict $\hat{y}$ for the independent validation period (2000-2015). While the synoptic RSME and $\mathrm{R}^{2}$ from cross-validation are useful model performance measures for accuracy and explanatory power respectively, the RSME and prediction score were calculated additionally based on validation with completely independent data. The latter is a measure for how much better the prediction is than predicting only the annual cycle. Finally, the entire procedure was repeated with a predictor set that excludes regional $2 \mathrm{~m}$ air temperatures, since this allows better interpretation of results in the context of underlying mechanisms. 


\subsection{GCM coupling and prediction of local-scale twenty-first century response}

Each of the MPI-ESM simulations were forced with boundary conditions for different twenty-first century climate forcing scenarios RCPs 2.6, 4.5 and 8.5. For these simulations, the same predictors described above (Sect. 2.5) were extracted from the model output. The index-based predictors (MEI, AAOI and PDOI) were reconstructed by projection of anomaly fields, created by subtracting the means, onto the loading patterns of the predictors used for model training to ensure a consistency in the meaning of index values (e.g. Mutz et al. 2015). The 24 ESD models were then directly applied to the predictor sets for the RCP2.6, RCP4.5 and RCP8.5 scenarios to generate a 21 st time series of local temperature responses for the weather stations' coordinates. Finally, seasonal (DJF, MAM, JJA, and SON) means, annual means and 20a climatologies (2040-2060 and 2080-2100) were calculated to provide summaries of $2 \mathrm{~m}$ air temperature response predictions for each station. Figure 4 outlines the general method applied in this study, including predictor construction, model training, predictor-reconstruction from twenty-first century GCM simulations and prediction of local temperature responses based on the coupling of ESD models to GCM-based estimates.

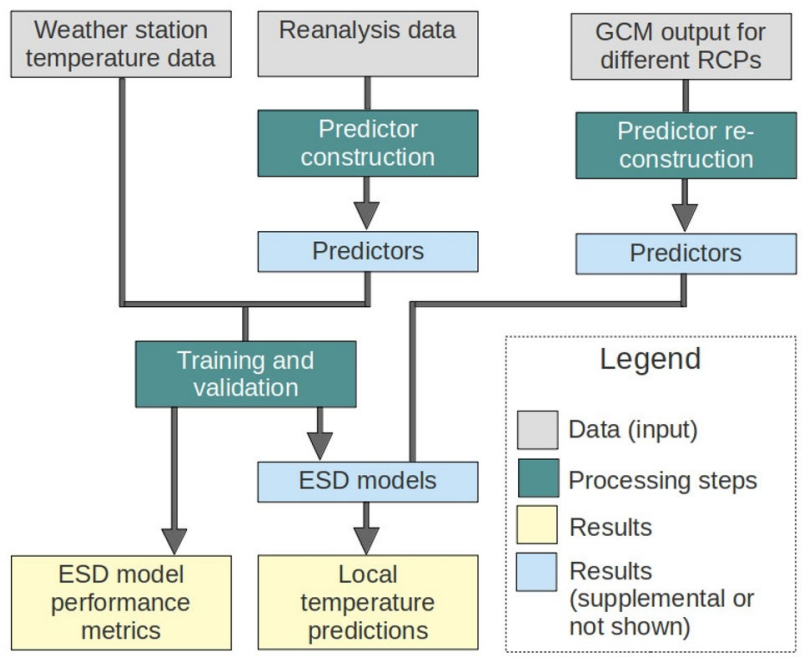

Fig. 4 Predictors for local temperature variability in Chile are created from reanalysis data. The constructed predictors and weather station temperature data are used in the model training and validation procedure to generate ESD (Empirical Statistical Downscaling) models and accompanying performance metrics for each of the weather stations. Predictors are reconstructed from GCM (General Circulation Model) output and drive the same ESD models to generate estimates of the local temperature response in Chile to twenty-first century climate change under different RCP forcing scenarios

\section{Results}

\subsection{Model summaries}

The training and validation procedure (Sect. 2.5) for the ESD models was carried out for all 24 stations, 3 training time periods (1979-2000, 2001-2015 and 1979-2015) and 2 subsets of predictors (the full set and the set omitting $\mathrm{t} 2 \mathrm{~m}$ ). This combination of parameters results in a total of 144 models. The focus of the results section lies on the models trained in 1979-2000, because they (a) can be validated in a completely separate period, (b) consider more data for training than models based on 2001-2015 observations, and (c) adhere to established conventions for the training period (e.g. CORDEX 2020). Following validation, these models were coupled to GCM outputs (Sect. 3.2). The exact model parameters for the 24 models trained with the full predictor set in 1979-2000 are listed in supplemental Table 1.

Three different metrics are used to assess the strength of the models. The RMSE can be interpreted as a measure of the overall model accuracy, while the score describes now much better the prediction is in comparison to predicting the annual cycle (supplemental table 2). The total explained variance of each model (Figs. 5,6) represents the amount of variability of the predictand time series, namely temperature anomalies at each weather station, that can be explained by the trained models. Since additive models are used, the total explained variance can be split into the fractions of the predictands' variance that can be explained by individual predictors. Since this the most intuitive and versatile measure allowing more indepth interpretation and discussion, the model descriptions focus primarily on this, while the other performance metrics (RMSE and scores) are included in the supplemental material (supplemental table 2).

The ESD models trained on 1979-2000 data with the full set of predictors (Table 2; MEI, AAOI, PDOI, t2m, msl, u850, v850, h700) are associated with explained variances of ca. 40-90\% (Fig. 5). The models' ability to explain predictand variance generally increases with (higher) latitude. The dominant predictors are $2 \mathrm{~m}$ air temperature and MEI, followed by regional pressure fields and meridional wind speed components. While the contribution of the MEI to the total explained variance is the greatest for most of the northern weather stations, it decreases with higher latitudes and creases to contribute significantly for stations south of Quintero $\left(32.8^{\circ} \mathrm{S}\right)$. The RMSE and scores range from 0.3 to 1.0 and 0.3 to 0.9 respectively (supplemental table 2). The scores increase with higher latitudes as is the case with explained variances. The exclusion of $\mathrm{t} 2 \mathrm{~m}$ from the predictor set results in lower 


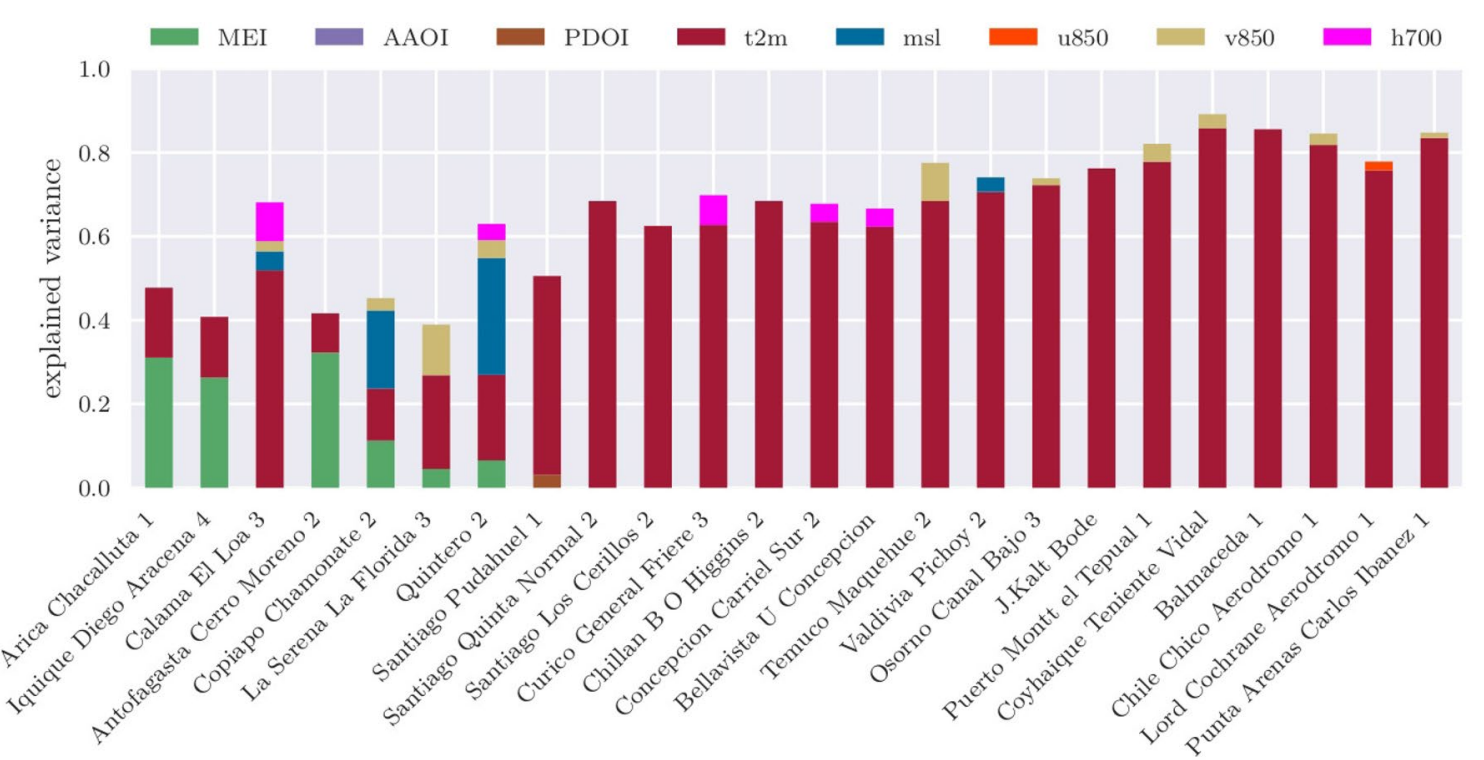

Fig. 5 Predictor-specific partial explained variances of weather station temperatures. Colours correspond to specific predictors and the stations are ordered from left to right by their latitudinal position (north to south). The complete predictor set consists of the Multivariate ENSO Index (MEI, green), Antarctic Oscillation Index (AAOI, purple), Pacific Decadal Oscillation Index (PDOI, brown), regional

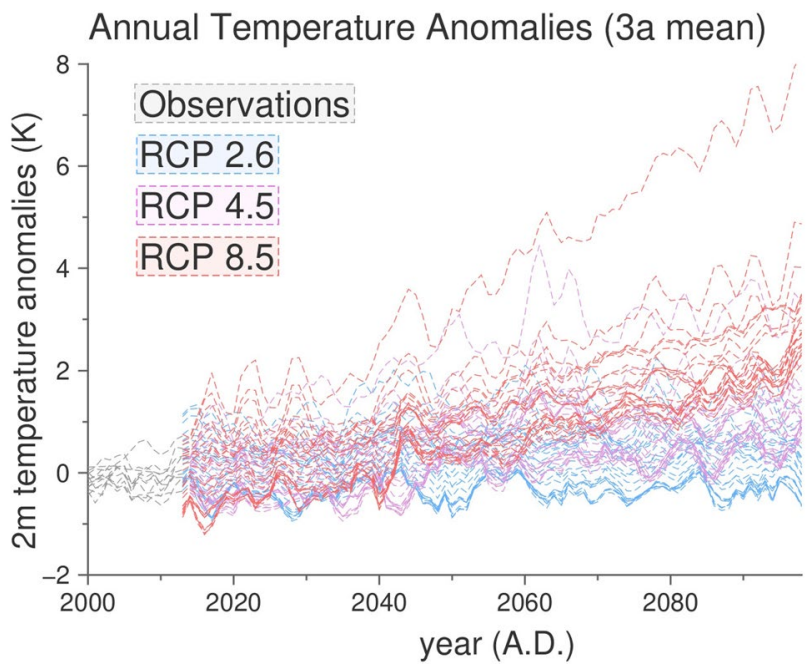

Fig. 6 3a moving average of twenty-first century mean annual temperature anomalies for each station as observed (grey) and estimated based on empirical-statistical downscaling models and GCM simulations forced with scenarios RCP2.6 (blue), RCP4.5 (purple) and RCP8.5 (red). The reference for anomalies are observation based long term means for 1979-2000

(30-70\%) explained variances especially in higher latitudes. Regional pressure fields are able to explain ca. 50\% of extratropical temperatures, and meridional and zonal wind speed components contribute additional 2-20\% and means of $2 \mathrm{~m}$ air temperature ( $\mathrm{t} 2 \mathrm{~m}$, red), regional means of mean sea level pressure (msl, blue), regional means of zonal wind speeds at $850 \mathrm{hPa}$ (u850, orange), regional means of meridional wind speeds at $850 \mathrm{hPa}(\mathrm{v} 850$, beige) and regional means of geopotential height at $700 \mathrm{hPa}(\mathrm{h} 700$, pink)

$2-8 \%$ respectively in Chile's temperate zone (supplemental figure S02).

\subsection{Downscaling of GCM simulations}

The coupling of the 24 models (Sect. 3.1) to twenty-first century global climate simulations forced with RCP2.6, RCP4.5 and RCP8.5 result in twenty-first century monthly time series for each station and RCP emission scenario. Results are presented as deviations from the respective annual temperature means at each station. For clarity, the annual means computed from these time series were low pass filtered using a 3 year moving arithmetic mean with central-year assignment (Fig. 6). The modelled regional responses to different RCPs only show a significant deviation from each other from mid-century onward. On the other hand, differences in 20a end-ofcentury climatologies (Fig. 7) are very pronounced with predicted responses ranging from ca. $-0.5-2 \mathrm{~K}, 0.5-3 \mathrm{~K}$ and 2-7 K for RCP2.6, RCP4.5 and RCP8.5 respectively. The stations experiencing the highest positive end-ofcentury temperature deviations also experience higher mid-century temperature deviations than other stations (supplemental figure S04). There is no apparent association between the magnitude of deviations and proximity to the ocean, latitude, altitude or annual means in the observation period. The construction of seasonal (DJF, MAM, JJA and SON) end-of-century 20a climatologies (Fig. 8) 


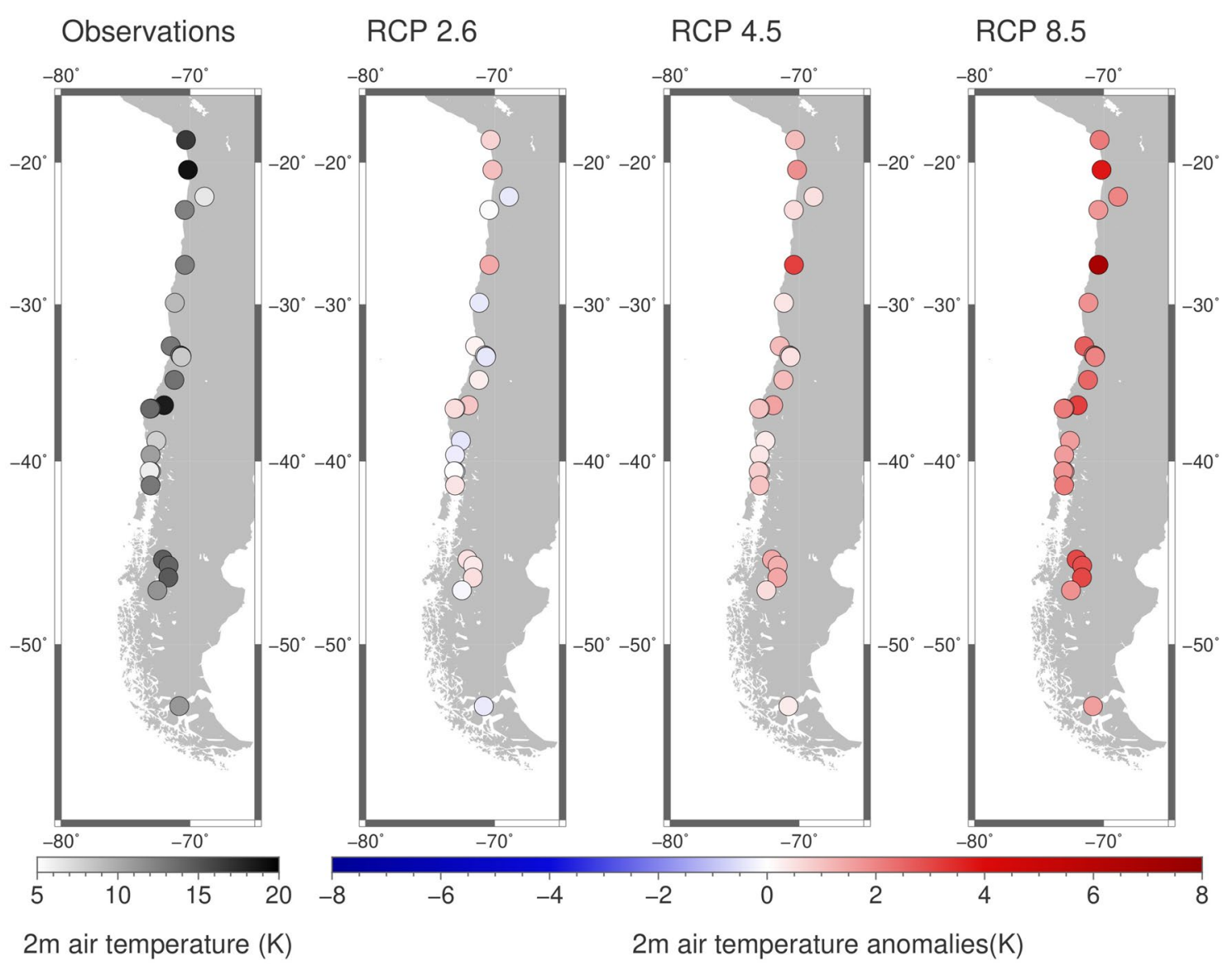

Fig. 7 Climatologies of observed mean annual temperatures (grey) and climatological anomalies of mean annual temperatures based on empirical-statistical downscaling models and GCM simulations forced with scenarios RCP2.6 (blue), RCP4.5 (purple) and RCP8.5 (red). RCP anomalies are based on end-of-century (2080-2100) means and reference climatologies created from 1979 to 2000 observations

of seasonal means (supplemental figure S05) show preferential warming in the same seasons.

\section{Discussion}

\subsection{Model evaluation and controls on regional temperatures}

Overall, the explained variances, RMSEs and scores of ESD models for regional temperatures were high (40-90\%, $0.3-0.9$ and up to 0.9 respectively), indicating a strong dependence between regional temperatures and large-scale atmospheric controls, as well as the ability of ERA-interim and the GCM (MPI-ESM) to adequately represent those. The previous model performance metrics indicate that the ESD-based predictions work best in Chile's higher latitudes, such as for the stations near Concepción and Punta Arenas. This finding is consistent with reports of downscaling producing better results in wet regions, particularly 


\section{Temperature Anomalies (2080-2100)}

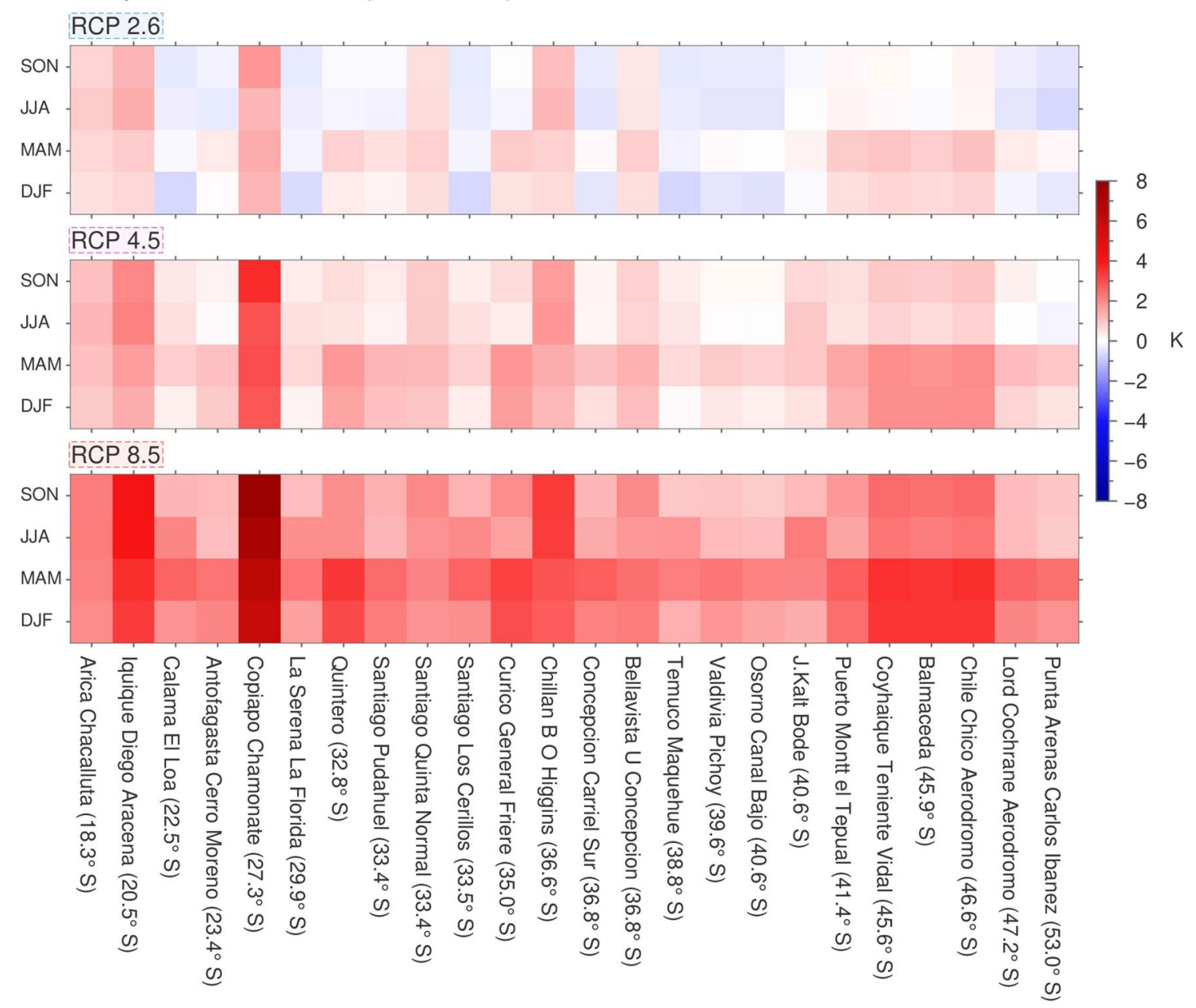

Fig. 8 End-of-century (2080-2100) climatological anomalies of mean seasonal temperatures based on empirical-statistical downscaling models and GCM simulations forced with scenarios RCP2.6 (top), RCP4.5 (middle) and RCP8.5 (bottom) for each station and sea-

in the mid-latitudes, than in dry regions (Cavazos and Hewitson 2005; Fowler et al. 2007). The high explained variances in these mid-latitudes by $2 \mathrm{~m}$ air temperature alone indicate that implicitly considered conditions and feedbacks in the vicinity of weather stations determine a large part of mid-latitude model parameters and appear to stay constant over the observational period. The scores and RMSEs that were computed for stations south of Santiago Pudahuel $\left(33.4^{\circ} \mathrm{S}\right)$ for in training period $1979-2000$ are similar to those computed for training period 2001-2015, which indicates very little change in the local geographical conditions and predictor-predictand relationships over the entire observational period. This temporal stationarity lends more confidence in the predicted twenty-first century regional temperature response based on higherlatitude $\left(33.4^{\circ} \mathrm{S}-5^{\circ} \mathrm{S} 3\right)$ models. The reasons for the highly variable scores and mostly lower explained variances and sons DJF (December-January-Febuary), MAM (March-April-May), JJA (June-July-August) and SON (September-October-November). The reference for anomalies are observation based long term means for 1979-2000

RMSEs for low-latitude stations in northern Chile $\left(18.3^{\circ}\right.$ $\mathrm{S}-33.4^{\circ} \mathrm{S}$ ) are varied. Generally, it can likely be attributed to non-stationarity of transfer functions due to different conditions in the training and validation periods, and to observational records not being sufficiently long to capture all prediction-relevant dynamics. For example, the selection of the MEI in the model training procedure suggests a more direct impact of ENSO on regional temperatures. The period 1979-2000 experienced 2 very strong $(\mathrm{MEI}=2.5-3)$ and 2 strong $(\mathrm{MEI} \approx 2) \mathrm{El} \mathrm{Niño}$ years, whereas the period 2001-2015 only experienced one strong El Niño year. Therefore, models for northern stations like Arica Chacalluta $\left(18.3^{\circ} \mathrm{S}\right)$, Iquique Diego Aracena $\left(20.5^{\circ} \mathrm{S}\right)$ and Antofagasta Cerro Moreno (23.4 S) do not have the same high skill (score $=0.5-0.8$ ) as the higher-latitude models despite the relatively long observation records at these stations. 
When coupled to Atmospheric Model Intercomparison Project (AMIP) style GCM experiments (Taylor et al. 2012) for the same observational period, the ESD models reproduce low frequency temperature oscillations well (cf. Examples in supplemental figure S03). Given that the GCM experiments are forced with updated observed sea surface temperatures, it is reasonable to expect temperatures that are controlled by large scale atmospheric oscillations like ENSO and PDO to be well predicted. This is on par with similar findings by Lau and Nath (1994) for ENSO, Hoerling et al. (2001) for NAO and Sutton and Hodson (2005) for AMO.

While $2 \mathrm{~m}$ air temperature has been demonstrated to be the most powerful predictor overall, it does not explain the underlying controlling mechanisms. ENSO has a strong direct influence in northern Chile, as apparent by the explained variances (Fig. 5 and supplemental figure S03), low frequency features and timing of minima and maxima (supplemental figure S04) in our models. On the other hand, temperatures in central and southern Chile are governed by frontal systems, as suggested by high explained variance by mean sea level pressure and $700 \mathrm{hPa}$ geopotential height fields (supplemental figure S03). Exclusion of the latter predictor resulted in its replacement by zonal winds at the $850 \mathrm{hPa}$ level (not shown here) for stations between $30^{\circ} \mathrm{S}$ and $40^{\circ} \mathrm{S}$, which further supports the influence of westerlies on Chilean climate (Garreaud et al. 2009). The AAOI has not proven a robust predictor despite the known influence of the AAO (e.g. Garreaud et al. 2009). This may be due to its variability already being captured by the regional means predictors. While the PDO has demonstrated to be of relevance to Chilean climate (e.g. Valdés-Pineda et al. 2018), its influence was not captured in the ESD models. This is likely due to the relatively short observational records that do not adequately cover the PDO's low-frequency fluctuation on scales of 15, 25, 50 and 70 years (Mantua and Hare 2002).

\subsection{Twenty-first century regional temperature response in Chile}

The RCP-specific ensembles of predicted temperature anomalies for each station begin to diverge significantly around the mid-century (2040-2050), resulting in end-of-century regional climates with annual mean temperatures that increase by ca. $-0.5-2 \mathrm{~K}, 0.5-3 \mathrm{~K}$ and $2-7 \mathrm{~K}$ for RCP2.6, RCP4.5 and RCP8.5 respectively. This warming is unevenly distributed among seasons, so that many of the stations experience accentuated warming during the austral summer (DJF) and autumn (MAM). Some stations show accentuated warming only in autumn, indicating a prolonged warm season. These changes in annual temperature means and seasonality likely impact vegetation, ecosystems, local industry, adaptation and conservation strategies. For example, these predicted changes modify the climatic factors considered in the classification of Chile's terrestrial ecosystems that are conducted to facilitate conservation efforts (MartínezTilleria et al. 2017).

\subsection{Comparison to other studies}

This study's selection of predictors is based on previous studies examining large-scale control on Chilean weather and climate (e.g. Rutllant and Fuenzalida 1991; Rutllant et al. 2003; Montecinos and Aceituno 2003; Garreaud et al. 2013; Valdés-Pineda et al. 2018). Our results consolidate their findings with some limitations: (1) The AAOI was not chosen as a robust large-scale predictor for regional temperatures. However, given the climatic setting and findings of previous studies (e.g. Garreaud et al. 2009), this is likely due to multicollinearity among predictors and the relevant AAOI variability already captured by other predictors like regional-scale temperature means. (2) The exclusion of the PDO as a robust predictor is likely caused by the weather station records that do not adequately cover the PDO's lowfrequency fluctuations and its influence on regional climate (e.g. Valdés-Pineda et al. 2018). Souvignet et al. (2010) performed ESD of temperature (and precipitation), but the study was regionally restricted to a watershed in north-central Chile. Prior to this study, no ESD-based modelling of twenty-first century temperature changes has been conducted with the spatial coverage and the 24 stations presented here.

\subsection{Assumptions and limitations}

ESD is based on the premise that large-scale atmospheric variability leads to local-scale changes in atmospheric conditions (von Storch 1995), and assumes that empirical relationships between predictors and predictands have an underlying physical relationships, so that the statistical transfer functions of the ESD models continue to be valid through time (Zorita and von Storch 1999). The latter is known as the assumption of temporal stationarity of transfer functions. This study has largely demonstrated the validity of this assumption for the completely independent validation period. While other studies demonstrated decent performance of related techniques for other regions in the preindustrial (Reichert et al. 1999) and Last Glacial Maximum (Vrac et al. 2007), temporal stationarity may not be given for more dramatically different climates and through geological time. Since highly localised effects of vegetation- and topography are only implicitly taken into consideration, changes in such geographical conditions would likely result in different optimal transfer functions.

Another major caveat concerns models, in which ENSO is an important predictor. The accuracy of predictions made by such models depends on the adequacy of ENSO representation and accuracy of ENSO prediction by the GCMs they are 
coupled to. CMIP5 coupled ocean-atmosphere GCMs only showed modest improvements in ENSO representation compared to CMIP3 models. These include slightly better representations of latent heat flux feedbacks, amplitude and seasonal phase locking (Bellenger et al 2014). However, many challenges in ENSO modelling remain. Persistent problems include inaccuracies in amplitude and phase lock, the simulation of the switch between positive and negative shortwave feedbacks in the eastern equatorial Pacific, which only $30 \%$ of CMIP5 models are able to achieve, and a significant, ableit reduced, cold bias in the western Pacific (Bellenger et al 2014). The GCM used in this study shows relatively good ENSO representation, as assessed by scores in primary characteristics of amplitude, structure, spectrum and seasonality (Bellenger et al 2014). Nevertheless, the modelled ENSO response to climate change strongly depends on the GCM and predictions vary even across models with better ENSO representation. The results of this study are therefore biased towards the MPI-ESM representation and prediction of ENSO and will likely improve only with more significant leaps in the accuracy of modelled ENSO characteristics and behaviour.

\section{Conclusions}

We presented a first step in empirical-statistical downscaling of temperatures across Chile based on digitised records from 24 weather stations provided by the DMC. We employed a cross-validated stepwise multiple linear regression with a literature-informed predictor set and perfect prognosis approach to train the ESD models. We then coupled these to GCM simulations forced with RCP2.6, RCP4.5 and RCP 8.5 scenario conditions to generate estimates for the regional twenty-first century temperature response to said scenarios. The key conclusions of this study are:

- Regional $2 \mathrm{~m}$ temperature means are the most robust predictors for temperatures of mid-latitude Chile, while the Multivariate ENSO Index explains most of the lowerlatitude temperature variance in northern Chile.

- The described approach and predictor set works well for the investigated stations. This is demonstrated by explained variances of up to $70 \%$ in northern Chile and up to ca. $90 \%$ in southern Chile and other performance metrics. The performance of mid-latitude models is higher than that of low-latitude models, suggesting the approach is more suitable for the westerlies dominated climate in Chile.

- Circulation based predictors based on pressure fields and winds explain up to ca. $50 \%$ and $70 \%$ weather station temperature variance in northern Chile and southern
Chile respectively when regional temperatures means are removed from the analysis.

- Downscaling based end-of-century local temperature responses range from $-0.5-2 \mathrm{~K}, 0.5-3 \mathrm{~K}$ and $2-7 \mathrm{~K}$ for the RCP2.6, RCP4.5 and RCP8.5 scenarios respectively. The warming for RCP4.5 and RCP8.5 is accentuated in summer and autumn (DJF, MAM) at several stations across Chile, suggesting a prolonged warm season.

There are numerous possible improvements for empiricalstatistical downscaling in Chile, and ways to build upon the approach of this study. These improvements could include (1) a refinement of predictors, such as an AAOI based on coastal Chile pressure fields to improve the prediction performance of circulation based predictors, (2) preparation and inclusion of additional weather station records to improve coverage and comparison to RCM based estimates, (3) the inclusion of other GCM simulations and investigation of ensembles to better assess the robustness of predictions and discrepancies in predictions arising from different modelled ENSO responses to climate change, and (4) the application of hybrid models to exploit the superior skills of random forests regressions within the observational range of values and the superior ability of parametric regression based models to predict values outside the observational range (e.g. Pollinger et al. 2017) to improve overall performance.

Acknowledgements The work was funded by the DFG priority programme EarthShape (SPP 1803; Grants EH329/17-2 and EH329/14-2 to T.A.E.). We acknowledge the World Climate Research Programme's Working Group on Coupled Modelling, which is responsible for CMIP, and we thank the climate modeling groups (the Max Planck Institute for Meteorology) for producing and making available their model output. For CMIP the U.S. Department of Energy's Program for Climate Model Diagnosis and Intercomparison provides coordinating support and led development of software infrastructure in partnership with the Global Organization for Earth System Science Portals. We additionally thank the European Centre for Medium Range Weather Forecasts for providing the ERA-Interim reanalysis data (Dee et al. 2011), and the Chile National Meteorological and Hydrological Service for making the weather station records available to us. Finally, we thank the helpful reviewer (anonymous) and the editor of this manuscript (Jian Lu).

Funding Open Access funding enabled and organized by Projekt DEAL. The work was funded by the DFG priority programme EarthShape (SPP 1803; Grants EH329/17-2 and EH329/14-2 to T.A.E.).

Availability of data and material The data used in this study is available through the organisations listed in acknowledgements.

\section{Compliance with ethical standards}

Conflict of interest The authors declare that they have no conflict of interest.

Open Access This article is licensed under a Creative Commons Attribution 4.0 International License, which permits use, sharing, adaptation, distribution and reproduction in any medium or format, as long 
as you give appropriate credit to the original author(s) and the source, provide a link to the Creative Commons licence, and indicate if changes were made. The images or other third party material in this article are included in the article's Creative Commons licence, unless indicated otherwise in a credit line to the material. If material is not included in the article's Creative Commons licence and your intended use is not permitted by statutory regulation or exceeds the permitted use, you will need to obtain permission directly from the copyright holder. To view a copy of this licence, visit http://creativecommons.org/licenses/by/4.0/.

\section{References}

Bellenger H, Guilyardi E, Leloup J, Lengaigne M, Vialard J (2014) ENSO representation in climate models: from CMIP3 to CMIP5. Clim Dyn 42:199-2018. https://doi.org/10.1007/s0038 2-013-1783-Z

Braconnot P, Harrison SP, Kageyama M, Bartlein PJ, Masson-Delmotte V, Abe-Ouchi A, Otto-Bliesner B, Zhao Y (2012) Evaluation of climate models using palaeoclimatic data. Nat Clim Change $2: 417-424$

Cavazos T, Hewitson B (2005) Performance of ncep-ncar reanalysis variables in statistical downscaling of daily precipitation. Clim Res 28(2):95-107

CORDEX (2020) http://cordex.org. Accessed 18 Apr 2020

Dee P, Uppala S, Simmons A, Berrisford P, Poli P, Kobayashi S, Andrae U, Balmaseda M, Balsamo G, Bauer P, Bechtold P, Beljaars A, van de Berg L, Bidlot J, Bormann N, Delsol C, Dragani R, Fuentes M, Geer A, Haimberger L, Healy S, Hersbach H, Hólm E, Isaksen L, Kållberg P, Köhler M, Matricardi M, McNally A, Monge-Sanz B, Morcrette J, Park B, Peubey C, de Rosnay P, Tavolato C, Thépaut J, Vitart F (2011) The era-interim reanalysis: configuration and performance of the data assimilation system. Q J R Meteorol Soc 137(656):553-597. https://doi.org/10.1002/ qj. 828

Diaz-Nieto J, Wilby RL (2005) A comparison of statistical downscaling and climate change factor methods: impacts on low flows in the river thames, united kingdom. Clim Change 69(2-3):245-268

Eden JM, Widmann M, Grawe D, Rast S (2012) Skill, correction, and downscaling of GCM-simulated precipitation. J Clim 25:39703984. https://doi.org/10.1175/jcli-d-11-00254.1

Errico RM, Stensrud DJ, Raeder KD (2001) Estimation of the error distributions of precipitation produced by convective parameterization schemes. Q J R Meteorol Soc 127:2495-2512. https://doi. org/10.1002/qj.49712757802

Fogt RL, Bromwich DH (2006) Decadal variability of the ENSO teleconnection to the high-latitude South Pacific governed by coupling with the southern annular mode. J Clim 19:979-997

Fowler HJ, Blenkinsop S, Tebaldi C (2007) Linking climate change modelling to impacts studies: recent advances in downscaling techniques for hydrological modelling. Int $\mathrm{J}$ Climatol 27(12):1547-1578. https://doi.org/10.1002/joc.1556

Garreaud RD, Vuille M, Compagnucci R, Marengo J (2009) Presentday south american climate. Palaeogeogr Palaeoclimatol Palaeoecol 281(3-4):180-195

Garreaud R, Lopez P, Minivielle M, Rojas M (2013) Large-scale control on the Patagonian climate. J Clim 26:215-230. https://doi. org/10.1175/jcli-d-12-00001.1

Gillett NP, Kell TD, Jones PD (2006) Regional climate impacts of the southern annular mode. Geophys Res Lett 33:L23704. https://doi. org/10.1029/2006GL027721

Giorgi F, Gutowski WJ (2013) Regional dynamical downscaling and the CORDEX initiative. Annu Rev Environ Resour 40:467-490. https://doi.org/10.1146/annurev-environ-102014-021217
Glahn H, Lowry D (1972) The use of model output statistics (MOS) in objective weather forecasting. J Appl Meteorol 11:1203-1211. https://doi.org/10.1175/1520-0450(1972)011\%3c1203:TUOMO $\mathrm{S} \% 3 \mathrm{e} 2.0 . \mathrm{CO} ; 2$

Hansen JA, Emanuel KA (2003) Forecast 4D-Var: exploiting model output statistics. Q J R Meteorol Soc 129:1255-1267. https://doi. org/10.1256/qj.01.75

Hastie T, Friedman J, Tibshirani R (2001) The elements of statistical learning. Springer series in statistics. Springer, New York. https ://doi.org/10.1007/978-0-387-21606-5

Haywood AM, Dowsett HJ, Otto-Bliesner B, Chandler MA, Dolan AM, Hill DJ, Lunt DJ, Robinson MM, Rosenbloom N, Salzmann U, Sohl LE (2010) Pliocene Model Intercomparison Project (PlioMIP): experimental design and boundary conditions (Experiment 1). Geosci Model Dev 3:227-242

Hennermann K (2016) Era-interim issues with cloud cover. https ://software.ecmwf.int/wiki/display/CKB/ERA-Interim+issue s+with+cloud+cover. Accessed 29 June 2018

Hewitson BC, Daron J, Crane RG, Zermoglio MF, Jack C (2014) Interrogating empirical-statistical downscaling. Clim Change 122:539. https://doi.org/10.1007/s10584-013-1021-z

Hoerling MP, Hurrell JW, Xu T (2001) Tropical origins for recent north atlantic climate change. Science 292(5514):90-92

Hogrefe C, Lynn B, Civerolo K, Ku J-Y, Rosenthal J, Rosenzweig C, Goldberg R, Gaffin S, Knowlton K, Kinney P (2004) Simulating changes in regional air pollution over the eastern united states due to changes in global and regional climate and emissions. J Geophys Res Atmos 109(D22)

Huth R (2002) Statistical downscaling of daily temperature in central Europe. J Clim 15(13):1731-1742

IPCC (2014) In: Climate change 2014: impacts, adaptation, and vulnerability. Part A: global and sectoral aspects. In: Field CB, Barros VR, Dokken DJ, Mach KJ, Mastrandrea MD, Bilir TE, Chatterjee M, Ebi KL, Estrada YO, Genova RC, Girma B, Kissel ES, Levy AN, MacCracken S, Mastrandrea PR, White LL (eds) Contribution of working group II to the fifth assessment report of the intergovernmental panel on climate change. Cambridge University Press, Cambridge

Lau N-C, Nath MJ (1994) A modeling study of the relative roles of tropical and extratropical sst anomalies in the variability of the global atmosphere-ocean system. J Clim 7(8):1184-1207. https:// doi.org/10.1175/1520-0442(1994)007h1184:AMSOTRi2.0.CO;2

Lowry DA, Glahn H (1969) An operational method for objectively forecasting probability of precipitation. In: Bulletin of the American Meteorological Society. American Meteorological Society 45 Beacon St, Boston, MA 02108-3693, vol 50, p 458

Mannig B, Müller M, Starke E, Merkenschlager C, Mao W, Zhi X, Podzun R, Jacob D, Paeth H (2013) Dynamical downscaling of climate change in Central Asia. Glob Planet Change 110:26-39. https://doi.org/10.1016/j.gloplacha.2013.05.008

Mantua NJ, Hare SR (2002) The pacific decadal oscillation. J Oceanogr 58(1):35-44

Martínez-Tilleria K, Núñez-Ávila M, León CA, Pliscoff O, Squeo FA, Armesto JJ (2017) A framework for the classification Chilean terrestrial ecosystems as a tool for achieving global conservation targets. Biodivers Conserv 26:2857-2876. https://doi.org/10.1007/ s10531-017-1393-x

Maussion F, Scherer D, Finkelnburg R, Richters J, Yang W, Yao T (2011) WRF simulation of a precipitation event over the Tibetan Plateau, China - an assessment using remote sensing and ground observations. Hydrol Earth Syst Sci 15:1795-1817. https://doi. org/10.5194/hessd-7-3551-2010

Meehl GA, Stocker TF, Collins WD, Friedlingstein P et al (2007) In: Solomon S, Qin D, Manning M, Chen Z, Marquis M, Averyt KB, Tignor M, Miller HL (eds) IPCC, 2007: climate change 2007: the physical science basis. Contribution of working group I to 
the fourth assessment report of the intergovernmental panel on climate change. Cambridge University Press, Cambridge

Michaelsen J (1987) Cross-validation in statistical climate forecast models. J Clim Appl Meteorol 26(11):1589-1600. https://doi. org/10.1175/1520-0450(1987)026\%3c1589:CVISCF\%3e2.0.CO;2

Montecinos A, Aceituno P (2003) Seasonality of the enso-related rainfall variability in central chile and associated circulation anomalies. J Clim 16(2):281-296. https://doi.org/10.1175/15200442(2003)016h0281:SOTERRi2.0.CO;2

Moss RH, Edmonds JA, Hibbard K, Manning MR, Rose SK, van Vuuren DP, Carter TR, Emori S, Kainuma M, Kram T, Meehl GA, Mitchell JFB, Nakicenovic N, Riahi K, Smith SJ, Stouffer RJ, Thomson AM, Weyant JP, Wilbanks TJ (2010) The next generation of scenarios for climate change research and assessment. Nature 463:747-756. https://doi.org/10.1038/nature08823

Mutz S, Paeth H, Winkler S (2015) Modelling of future mass balance changes of Norwegian glaciers by application of a dynamical-statistical model. Clim Dyn. https://doi.org/10.1007/s0038 2-015-2663-5

Mutz SG, Ehlers T, Werner M, Lohmann G, Stepanek C, Li J (2018) Estimates of Late Cenozoic climate change relevant to Earth surface processes in tectonically active orogens. Earth Surf Dyn 6:271-301. https://doi.org/10.5194/esurf-6-271-2018

NOAA-CPC (2020) https://www.cpc.ncep.noaa.gov/products/precip/ CWlink/daily_ao_index/aao/aao.loading.shtml. Accessed 17 Apr 2020

Paeth H (2011) Postprocessing of simulated precipitation for impact research in West Africa. Part I: model output statistics for monthly data. Clim Dyn 36:1321-1336. https://doi.org/10.1007/s0038 2-010-0760-z

Patz JA, Campbell-Lendrum D, Holloway T, Foley JA (2005) Impact of regional climate change on human health. Nature 438(7066):310

Pollinger F, Ziegler K, Paeth H (2017) Comparison of the performance of three types of multiple regression for phenology in Bavaria in a dynamical-statistical model approach. Erdkunde 71(4):271-285

Reichert BK, Bengtsson L, Åkesson O (1999) A statistical modeling approach for the simulation of local paleoclimatic proxy records using general circulation model output. J Geophys Res 104:19071-19083. https://doi.org/10.1029/1999JD900264

Roberts DR, Bahn V, Ciuti S, Boyce MS, Elith J, Guillera-Arroita G, Hauenstein S, Lahoz-Monfort JJ, Schröder B, Thuiller W, Warton DI, Wintle BA, Hartig F, Dormann CF (2017) Crossvalidation strategies for data with temporal, spatial, hierarchical, or phylogenetic structure. Ecography 40(8):913-929. https://doi. org/10.1111/ecog.02881

Rogers JC, van Loon H (1982) Spatial variability of sea level pressure and $500 \mathrm{mb}$ height anomalies over the southern hemisphere. Mon Weather Rev 110(10):1375-1392. https://doi.org/10.1175/15200493(1982)110h1375:SVOSLPi2.0.CO;2

Rutllant JA, Fuenzalida H (1991) Synoptic aspects of the central chile rainfall variability associated with the southern oscillation. Int $\mathbf{J}$ Climatol 11(1):63-76. https://doi.org/10.1002/joc.3370110105

Rutllant JA, Fuenzalida H, Aceituno P (2003) Climate dynamics along the arid northern coast of Chile: The 1997-1998 dinámica del clima de la región de antofagasta (diclima) experiment. J Geophys Res Atmos 108(D17):4538. https://doi.org/10.1029/2002J D003357

Schulz N, Boisier JP, Aceituno P (2011) Climate change along the arid coast of northern Chile. Int J Climatol 32:1803-1814

Shongwe ME, Landman WA, Mason SJ (2006) Performance of recalibration systems for GCM forecasts for southern Africa. Int J Climatol 26:1567-1585. https://doi.org/10.1002/joc.1319

Solman SA (2013) Regional climate modeling over South America: a review. Adv Meteorol 2013:1-13. https://doi. org/10.1155/2013/504357

Souvignet M, Gaese H, Ribbe L, Kretschmer N, Oyarzún R (2010) Statistical downscaling of precipitation and temperature in northcentral Chile: an assessment of possible climate change impacts in an arid Andean watershed. Hydrol Sci J 55(1):41-57

Sutton RT, Hodson DL (2005) Atlantic ocean forcing of north American and European summer climate. Science 309(5731):115-118

Takahashi K, Battisti D (2007) Processes controlling the mean tropical pacific precipitation pattern. Part I: The Andes and the eastern Pacific ITCZ. J Clim 20(14):3434-3451

Taylor KE, Stouffer RJ, Meehl GA (2012) An overview of CMIP5 and the experiment design. Bull Am Meteorol Soc 93:485-498

Thompson DWJ, Wallace (2000) Annular modes in the extratropical circulation. Part I: month-to-month variability. J Clim 13(5):1000 1016. https://doi.org/10.1175/1520-0442(2000)013<1000:AMITE $\mathrm{C}>2.0 . \mathrm{CO} ; 2$.

Valdés-Pineda R, Cañón J, Valdés JB (2018) Multi-decadal 40-to 60 -year cycles of precipita-tion variability in chile (south america) and their relationship to the AMO and PDO signals. J Hydrol 556:1153-1170

Von Storch H (1995) Inconsistencies at the interface between climate research and climate impact studies. Meteor Z 4:72-80

Von Storch H, Zwiers F (1999) Statistical analysis in climate research. Cambridge University Press, Cambridge, p 496

Vrac M, Marbaix P, Paillard D, Naveau P (2007) Non-linear statistical downscaling of present and LGM precipitation and temperatures over Europe. Clim Past 3:669-682. https://doi.org/10.5194/ ср-3-669

Wolter K, Timlin M (1993) Monitoring enso in coads with a seasonally adjusted principalcomponent index. In: Proceedings of the 17th climate diagnostics workshop, pp 52-57

Wolter K, Timlin M (2011) El niño/southern oscillation behaviour since 1871 as diagnosed inan extended multivariate ENSO index (mei.ext). Int J Climatol 31(7):1074-1087. https://doi. org/10.1002/joc. 2336

Zorita E, von Storch H (1999) The analog method as a simple statistical downscaling technique: comparison with more complicated methods. J Clim 12:2474-2489

Publisher's Note Springer Nature remains neutral with regard to jurisdictional claims in published maps and institutional affiliations. 